\title{
Potentiating activities of chrysin in the therapeutic efficacy of 5-fluorouracil in gastric cancer cells
}

\author{
SUNYI LEE ${ }^{1,2}$, SUK KYEONG LEE ${ }^{3}$ and JOOHEE JUNG ${ }^{1,2}$ \\ ${ }^{1}$ Duksung Innovative Drug Center and ${ }^{2}$ College of Pharmacy, Duksung Women's University, Seoul 01369; \\ ${ }^{3}$ Department of Medical Life Sciences, Department of Biomedicine and Health Sciences, \\ College of Medicine, The Catholic University of Korea, Seoul 06591, Republic of Korea
}

Received August 16, 2019; Accepted September 24, 2020

DOI: $10.3892 / \mathrm{ol} .2020 .12285$

\begin{abstract}
The incidence and mortality rates of gastric cancer rank among the highest five of all cancer types worldwide. The chemotherapeutic agent 5-fluorouracil (5-FU) is the gold standard for treating gastric cancer, but its efficacy is limited due to high rates of resistance. To improve the therapeutic efficacy of 5-FU and overcome its resistance, the synergistic effect of chrysin with 5-FU was investigated and its mechanism was elucidated. Chrysin was co-administered with 5-FU in AGS cells and 5-FU-resistant AGS cells (AGS/FR). Cytotoxicity was investigated using MTT assay, followed by calculating the combination index (CI). Several biomarkers were detected using western blotting analysis. Apoptosis and cell cycle distribution were measured by flow cytometry. The combination of chrysin and 5-FU significantly increased cytotoxicity more than chrysin or 5-FU alone. 5-FU induced apoptosis through p53-p21 activity, while chrysin arrested the cell cycle in the G2/M phase. The combination of chrysin and 5-FU showed an anticancer effect via $\mathrm{S}$ phase arrest. The results indicated that chrysin and 5-FU exhibited anticancer properties via different pathways. Furthermore, the present study found that chrysin enhanced the chemotherapeutic effect of 5-FU in AGS/FR cells. In the resistant cells, the combination of chrysin and 5-FU improved the anticancer effect via G2/M phase arrest. These findings indicated that chrysin potentiated the chemotherapeutic effect of 5-FU in gastric cancer AGS and AGS/FR cells via cell cycle arrest. Therefore, chrysin may be used to treat gastric cancers that have become resistant to 5-FU.
\end{abstract}

\section{Introduction}

Gastric cancer is the fifth most frequently diagnosed cancer type and the third leading cause of cancer-associated mortality (1).

Correspondence to: Dr Joohee Jung, College of Pharmacy, Duksung Women's University, 33 Samyang-ro 144-gil, Dobong-gu, Seoul 01369, Republic of Korea

E-mail: joohee@duksung.ac.kr

Key words: chrysin, synergic effect, gastric cancer, 5-fluorouracil, cell cycle arrest
To treat gastric cancer, surgery is effective but often restrictive. Therefore, chemotherapy is the main therapy for patients with advanced gastric cancer. Among them, 5-fluorouracil (5-FU) is one of the most commonly used chemotherapeutic agents for patients with gastric cancer. The anticancer mechanism of 5-FU is via inhibition of thymidylate synthase, which is necessary for the synthesis of intracellular DNA, and the suppression of cell function by inhibiting RNA function and production (2). However, numerous patients become resistant to chemotherapy, limiting the efficacy of commonly used anticancer drugs. The mechanisms of chemotherapy resistance include reducing intracellular drug accumulation, increasing drug efflux, increasing nucleotide repair activity and avoiding apoptosis (3). In particular, multidrug resistance protein (MDR) serves an important role in drug efflux, causing drug resistance $(4,5)$. In gastric cancer, $\sim 21 \%$ of patients show progressive resistance to 5-FU (6). Therefore, a novel chemotherapeutic agent for gastric cancer is required to overcome drug resistance.

Chrysin (5,7-dihydroxyflavone) is a biologically active flavonoid derived from plants and natural products, including propolis (7). Chrysin possesses anticancer effects through numerous mechanisms, including cell cycle arrest through inhibition of histone deacetylase (8), autophagic cell death (9), suppression of the Jun N-terminal kinase (JNK) pathway (10) and apoptosis (11). Furthermore, chrysin inhibits $\mathrm{P}$-glycoprotein (P-gp), multidrug resistance-related protein (MRP)-2 and breast cancer resistance protein (BCRP). It acts as an MDR reversing agent in colon carcinoma cells (12) and breast cancer cells (13). These multiple functions of chrysin suggest that it may be effective in combination chemotherapy.

Therefore, in the present study, the combined effect of chrysin and 5-FU was investigated in gastric cancer AGS cells. Furthermore, the effect of chrysin was also investigated in 5-FU-resistant AGS (AGS/FR) cells.

\section{Materials and methods}

Cell culture. Human gastric cancer AGS cells were purchased from the Korean Cell Line Bank (no. 21739). AGS/FR cells were provided by The Catholic University of Korea. These cells were incubated with RPMI-1640 medium (GenDEPOT), supplemented with $10 \%$ fetal bovine serum (GenDEPOT) and 
$1 \%$ penicillin/streptomycin (GenDEPOT). AGS/FR cells were cultured in medium containing $100 \mu \mathrm{M}$ 5-FU (Sigma-Aldrich; Merck KGaA) to maintain resistance.

Measurement of cell viability. AGS and AGS/FR cells were seeded onto 96 -well plates at $0.5-1.0 \times 10^{4}$ cells/well and incubated for 24 h. Chrysin (Sigma-Aldrich; Merck KGaA) and 5-FU were diluted in $0.5 \%$ dimethyl sulfoxide (DMSO) solution (Sigma-Aldrich; Merck KGaA) and the cells were treated for 24 or $48 \mathrm{~h}$. For the cell viability assay, these cells were measured using an MTT assay (14). In brief, MTT (Sigma-Aldrich; Merck KGaA) was added to the media for $3 \mathrm{~h}$, and then the media were removed. DMSO was added to the cells for $30 \mathrm{~min}$. Absorbance was measured using a microplate reader (Infinite M200 PRO; TECAN) at $560 \mathrm{~nm}$.

Calculation of Combination Index (CI). To evaluate the combined effect of chrysin and 5-FU, the Chou-Talalay method was used (15) and the CI value was calculated using the Calcusyn 2.0 program (Biosoft). The resulting CI value showed quantitation for the synergistic effect $(\mathrm{CI}<1)$, additive effect $(\mathrm{CI}=1)$ or antagonism $(\mathrm{CI}>1)$.

Cell morphology. Cells were treated with $50 \mu \mathrm{M}$ chrysin, $25 \mu \mathrm{M} 5$-FU, or a combination of chrysin and 5-FU for $24 \mathrm{~h}$. Change of cells morphology was confirmed through an inverted microscope (magnification, $\mathrm{x} 40$ ) (Nikon ECLIPSE TS 100; Nikon Corporation).

Apoptosis staining. Cells were treated with $50 \mu \mathrm{M}$ chrysin, $25 \mu \mathrm{M} 5$-FU, or a combination of chrysin and 5-FU for $24 \mathrm{~h}$. To measure apoptosis, cells were washed with cold phosphate-buffered saline (PBS) and resuspended. The staining solution of Annexin V-FITC (BD Pharmingen) and propidium iodide (PI) was added to the cells and gently mixed. The cells were incubated at room temperature for $15 \mathrm{~min}$ in the dark. The cells were analyzed using a flow cytometer ACEA Novocyte 2000 (Agilent Technologies, Inc.). The data was analyzed using the NovoExpress ${ }^{\circledR}$ software version 1.2.5 (Agilent Technologies, Inc.).

Cell cycle analysis. Cells were treated with $50 \mu \mathrm{M}$ chrysin, $25 \mu \mathrm{M} 5-\mathrm{FU}$, or the combination of chrysin and 5-FU for $24 \mathrm{~h}$. For cell cycle analysis (16), the collected cells were washed with cold PBS. After centrifugation at room temperature (244 x g for $2 \mathrm{~min}$ ), the cell pellet was fixed with $70 \%$ ethanol overnight at $-20^{\circ} \mathrm{C}$. The fixed cells were centrifuged at room temperature ( $244 \mathrm{x} \mathrm{g}$ for $2 \mathrm{~min}$ ) and supernatant was removed. Cells were treated with PI solution and incubated for $30 \mathrm{~min}$ at room temperature. Stained cells were analyzed using a flow cytometer flow cytometer ACEA Novocyte 2000 (Agilent Technologies, Inc.). The data was analyzed using the NovoExpress ${ }^{\circledR}$ software version 1.2.5 (Agilent Technologies, Inc.).

Western blotting. Expression levels of cell death-related proteins were determined by western blot analysis (17). Cells were treated with chrysin $(50 \mu \mathrm{M}), 5$-FU $(25 \mu \mathrm{M})$, or the combination of chrysin and 5-FU for $24 \mathrm{~h}$. Cells were lysed in RIPA buffer (GenDEPOT) with protease inhibitors (GenDEPOT) and phosphatase inhibitors (Roche, Basel). Protein concentration was measured using Pierce ${ }^{\mathrm{TM}}$ bicinchoninic acid protein assay kit (cat. no. 23225; Thermo Fisher Scientific, Inc.). The proteins (15 $\mu \mathrm{g} / \mathrm{lane})$ separated from cell lysates by $10-15 \%$ SDS-polyacrylamide gel electrophoresis were transferred onto polyvinylidene fluoride membranes (Merck Millipore). Membranes were blocked with $5 \%$ skimmed milk in tris-buffered saline with $0.1 \%$ Tween 20 for $1 \mathrm{~h}$ at room temperature, and then incubated with primary antibodies against p53 (1:1,000; cat. no. 05-224; Merck KGaA); p21WAF1/Cip1 (1:2,000; cat. no. 05-345; Merck KGaA); Bax (1:1,000; cat. no. 610982; BD Biosciences); Caspase 9 (1:1,000; cat. no. 9508; Cell Signaling Technology, Inc.); cleaved Caspase 9 (1:1,000; cat. no. 7237; Cell Signaling Technology, Inc.); Caspase 3 (1:1,000; cat. no. 9665; Cell Signaling Technology, Inc.), cleaved Caspase 3 (1:1,000; cat. no. 9664; Cell Signaling Technology, Inc.), phospho-Akt (1:1,000; cat. no. 4060; Cell Signaling Technology, Inc.); Akt (1:1,000; cat. no. 9272; Cell Signaling Technology, Inc.); cyclin D1 (1:1,000; cat. no. 2978; Cell Signaling Technology, Inc.); CDK6 (1:1,000; cat. no. 3136; Cell Signaling Technology, Inc.), cdc2 (1:1,000; cat. no. 77055; Cell Signaling Technology, Inc.); cyclin B1 (1:1,000; cat. no. 12231; Cell Signaling Technology, Inc.), MDR1 (1:1,000; cat. no. sc-55510; Santa Cruz Biotechnology, Inc.) and $\beta$-actin (1:5,000; cat. no. A 5441; Sigma-Aldrich; Merck KGaA) overnight at $4^{\circ} \mathrm{C}$. The next day, membranes were incubated with the following secondary antibodies for $3 \mathrm{~h}$ at room temperature: Goat anti-mouse $\operatorname{IgG}(\mathrm{H}+\mathrm{L})$-horseradish peroxidase (HRP)-conjugated (1:3,000; cat. no. 1706516; BioRad Laboratories, Inc.) and goat anti-rabbit $\operatorname{IgG}(\mathrm{H}+\mathrm{L})$-HRP-conjugated $(1: 3,000$; cat. no. 1706515; BioRad Laboratories, Inc.). Proteins were detected by Chemi-Doc (FluorChem E system; ProteinSimple) using enhanced chemiluminescent (ECL) solution [to use, mix solution A comprised of $250 \mathrm{mM}$ luminol (Sigma-Aldrich; Merck KGaA), $90 \mathrm{mM}$ p-Coumaric acid (Sigma-Aldrich; Merck KGaA) and $1 \mathrm{M}$ Tris- $\mathrm{HCl}(\mathrm{pH}$ 8.5) (Duchefa Biochemie B.V) and $\mathrm{B}$ comprised of $1 \mathrm{M}$ Tris- $\mathrm{HCl}(\mathrm{pH} 8.5)$ (Duchefa Biochemie B.V) and $\mathrm{H}_{2} \mathrm{O}_{2}$ (DSP Inc.) in a 1:1 ratio] and analyzed using AlphaView software for FluoChem E system (version 3.4.0, Proteinsimple Inc.).

Statistical analysis. The data were analyzed using one-way and two-way analysis of variance, followed by Tukey's post hoc test to statistically analyze differences among multiple groups. The statistical analyses were performed using GraphPad Prism 7 (GraphPad Software Inc.). All data are shown as the mean \pm standard deviation. $\mathrm{P}<0.05$ was considered to indicate a statistically significant difference.

\section{Results}

Synergistic effect of chrysin and 5-FU in AGS and AGS/FR cells. The viability of AGS cells in response to chrysin, 5-FU, or the combination of chrysin and 5-FU were evaluated with increasing doses (Fig. 1A). Conditions 1, 2, 3 and 4 referred to chrysin doses of 40, 50, 60 and $80 \mu \mathrm{M}$, and 5-FU doses of 20, 25,30 and $40 \mu \mathrm{M}$, respectively. The combination of chrysin and 5-FU significantly inhibited cell viability more than 5 -FU alone (Fig. 1A). In particular, conditions 1 and 2 for 5-FU + chrysin 

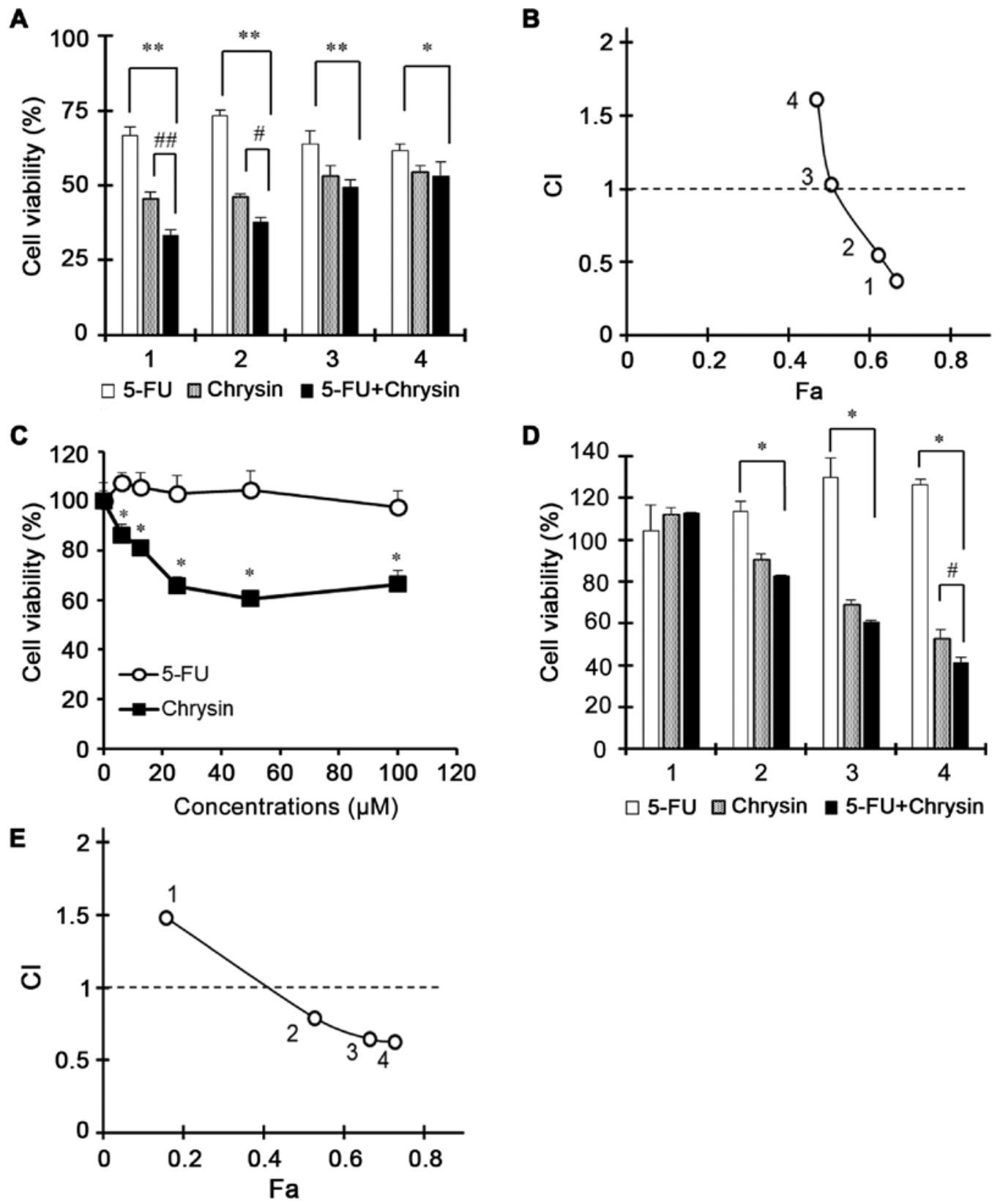

Figure 1. Synergistic effect of chrysin and 5-FU in AGS and AGS/FR cells. AGS cells were treated with chrysin, 5-FU or the combination of chrysin and 5-FU for $24 \mathrm{~h}$. AGS/FR cells were treated with chrysin, 5-FU or the combination of chrysin and 5-FU for 24 and $48 \mathrm{~h}$. Treated conditions 1,2, 3 and 4 were as follows: (A and B) 40,50,60 and $80 \mu \mathrm{M}$ for chrysin, and 20,25,30 and $40 \mu \mathrm{M}$ for 5-FU, respectively, in AGS cells; and (D and E) $20,40,50$ and $60 \mu \mathrm{M}$ for chrysin, and 6.25, 12.5, 25 and $50 \mu \mathrm{M}$ for 5-FU, respectively in AGS/FR cells. (A, C, D) Cell viability was measured by MTT assay. (A) Data are presented as the mean $\pm \mathrm{SD} ;{ }^{*} \mathrm{P}<0.01 ;{ }^{* *} \mathrm{P}<0.001 ;{ }^{\# \mathrm{P}}<0.01 ;{ }^{\# /} \mathrm{P}<0.001$ (two-way ANOVA). (C) Data are presented as the mean $\pm \mathrm{SD} ;{ }^{*} \mathrm{P}<0.001$ (one-way ANOVA). (D) Data are presented as the mean $\pm \mathrm{SD}$; $\mathrm{P}<0.001 ;{ }^{*} \mathrm{P}<0.05$ (two-way ANOVA). 5-FU, 5 -fluorouracil; $\mathrm{CI}$, combination index; Fa, fractional effect; SD, standard deviation; ANOVA, analysis of variance.

potentiated the inhibition of cell viability more than 5-FU or chrysin alone. To calculate the combined effect, combination index $(\mathrm{CI})$ values for each condition were compared and exhibited an antagonistic $(>1)$, addictive $(=1)$ or synergistic $(<1)$ effect. As shown in Fig. 1B, CI values of conditions 1, 2, 3 and 4 were $0.371,0.548,1.030$ and 1.614 , respectively. These results suggested that the combined treatment serves a role in the inhibition of cell viability. Furthermore, addictive or synergistic effects of $24 \mathrm{~h}$ treatment similarly showed synergistic effects in the same conditions as $48 \mathrm{~h}$ treatment (Fig. S1).

Furthermore, the effect of chrysin or the combination of chrysin and 5-FU was investigated in 5-FU-resistant gastric cancer AGS/FR cells. Chrysin significantly inhibited cell viability in AGS/FR cells (Fig. 1C). In particular, the combination of chrysin and 5-FU for $48 \mathrm{~h}$ showed a synergistic effect in the inhibition of cell viability (Fig. 1D). For these experiments, conditions $1,2,3$ and 4 referred to chrysin doses at 20, 40, 50 and $60 \mu \mathrm{M}$, and 5-FU doses at 6.25, 12.5, 25 and $50 \mu \mathrm{M}$, respectively. Although AGS/FR cells remained viable following 5-FU $100 \mu \mathrm{M}$ treatment, the viability of the cells was significantly suppressed with the combination of chrysin and 5-FU more than chrysin alone (Fig. 1D). Furthermore, CI values in conditions 2,3 , and 4 were $0.79,0.64$ and 0.62 , indicating a synergistic effect at each of these doses (Fig. 1E). 

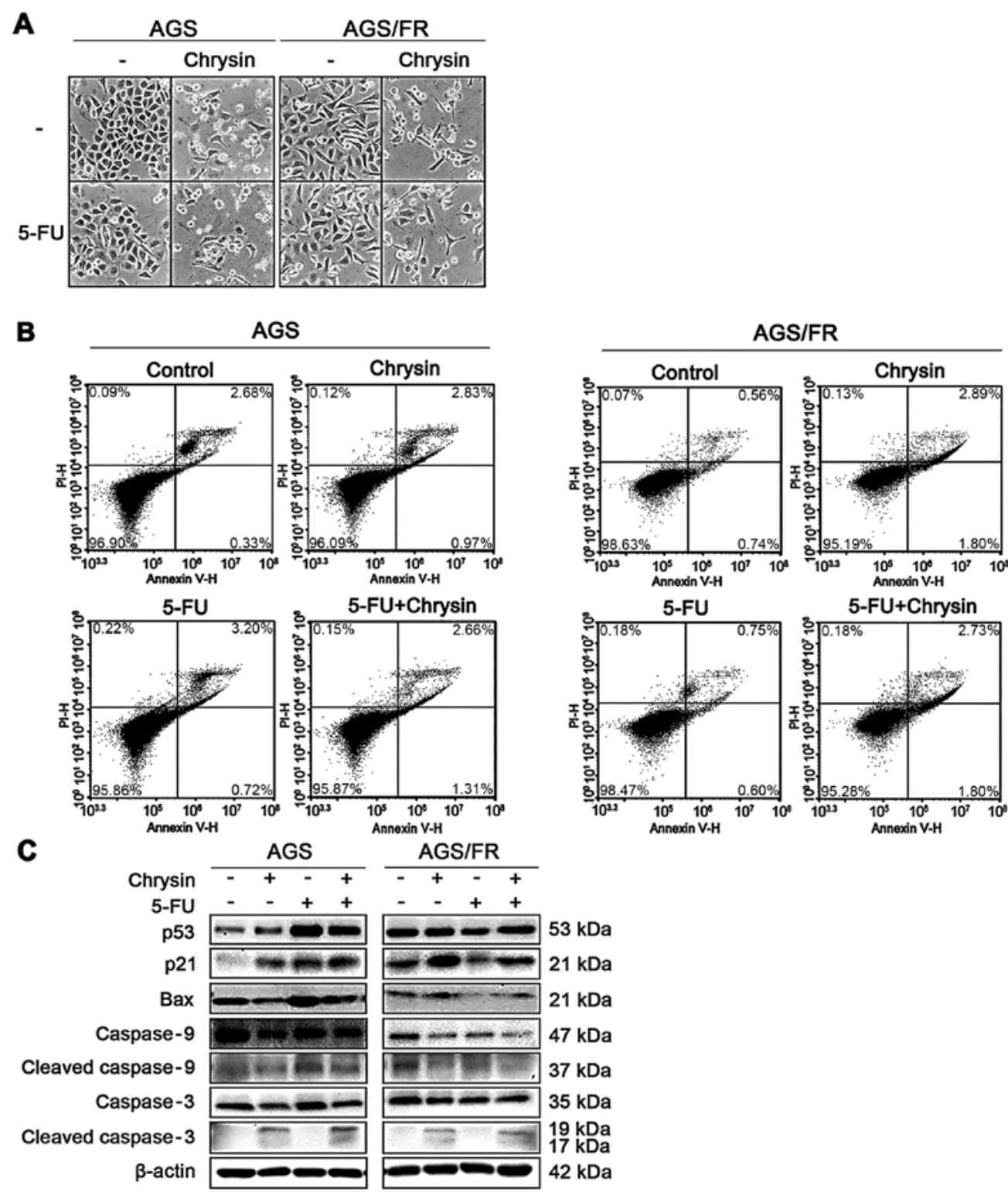

Figure 2. Induction of apoptosis by chrysin and 5-FU in AGS and AGS/FR cells. Cells were treated under common conditions (condition 2 in AGS cells; condition 3 in AGS/FR cells) for $24 \mathrm{~h}$. (A) Cell morphology was observed using a microscope (magnification, x40). (B) Apoptosis was detected in AGS and AGS/FR cells by Annexin V and PI staining. (C) Protein expression levels were detected using western blotting. 5-FU, 5-fluorouracil; PI, propidium iodide.

These results suggested that chrysin improved the cytotoxicity of 5-FU in AGS and AGS/FR cells.

Apoptosis of AGS and AGS/FR cells following treatment with chrysin and 5-FU. Common condition (condition 2 in AGS cells; condition 3 in AGS/FR cells) doses were used for further chrysin/5-FU combination studies. Under these conditions, each cellular morphology is shown in Fig. 2A.

To elucidate the mechanism of the synergistic anticancer effect shown in Fig. 1B and E, the cells were stained using annexin V-PI solution and analyzed by flow cytometry. Chrysin and the combination of chrysin and 5-FU caused more apoptosis than the control in AGS and AGS/FR cells; however, 5-FU caused more apoptosis only in AGS cells (Fig. 2B). Some cells in Fig. 2B were shown to be slightly spread, including control. This result is speculated to be caused by the solvent DMSO. Therefore, the expression levels of apoptosis-related proteins were further investigated by western blotting. Semi-quantitative analysis of these protein levels are shown in Fig. S2 (three repeats). In AGS cells, 5-FU, chrysin and the combination of chrysin and 5-FU increased p53 and p21; however, 5-FU caused no change of these protein expression levels in AGS/FR cells (Fig. 2C). These results suggested that chrysin inhibited cell viability via a different pathway than that of 5-FU. Therefore, the complementary mechanism of the combined treatment was investigated.

Potentiated anticancer effect of chrysin occurs via G2/M phase arrest. As an increase in the $\mathrm{p} 21$ level induced by chrysin was observed in the western blot analysis, the cell cycle was further evaluated in AGS and AGS/FR cells.

Chrysin induced cell arrest in the G2/M phase, while 5 -FU induced arrest in the G0/G1 phase in AGS cells. The combination of chrysin and 5-FU showed cell cycle arrest 

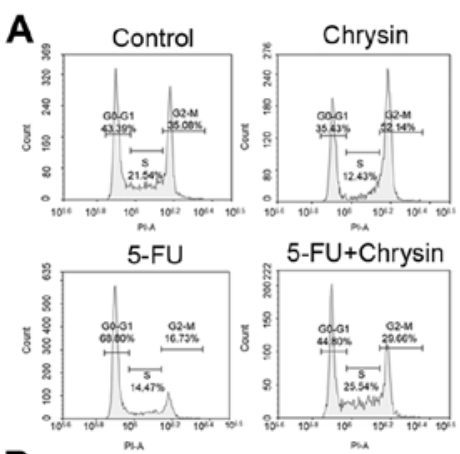

B
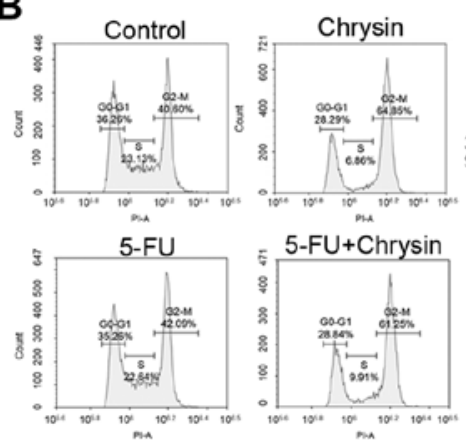
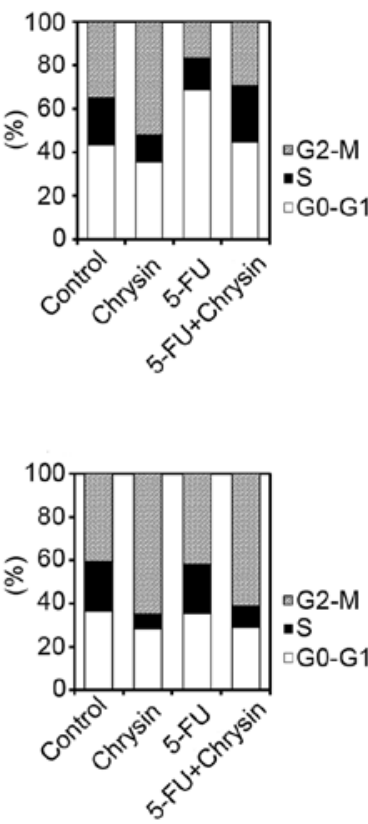

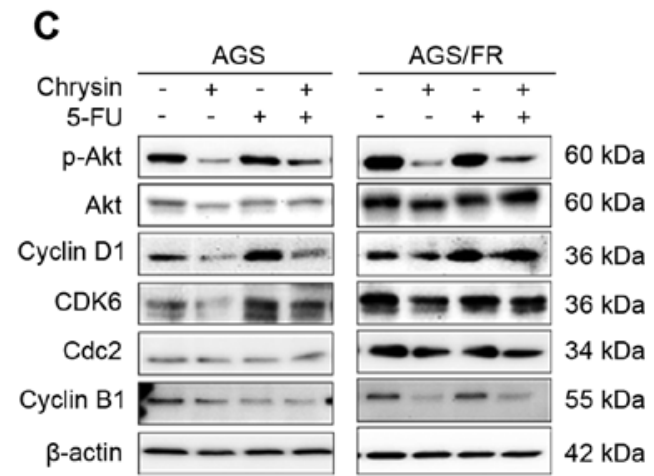

Figure 3. Chrysin improves the anticancer effect of 5-FU through cell cycle arrest. Cells were treated with $50 \mu \mathrm{M}$ chrysin and $25 \mu \mathrm{M} 5$-FU for $24 \mathrm{~h}$. Cell distribution was analyzed by flow cytometry in (A) AGS cells and (B) AGS/FR cells. (C) Protein levels were detected using western blotting. 5-FU, 5-fluorouracil.

in the S phase (Fig. 3A). However, chrysin (64.85\%) and the combination of chrysin and 5-FU (61.25\%) accumulated cells in the $\mathrm{G} 2 / \mathrm{M}$ phase more than control treatment $(40.6 \%)$ in AGS/FR cells (Fig. 3B). Cell cycle-related protein levels were measured by western blotting (Fig. 3C). The combination of chrysin and 5-FU also decreased cyclin B1, cell cycle division cycle protein 2 (cdc2) and suppressed phosphorylated Akt (p-Akt) expression in AGS cells. The combination of chrysin and 5-FU showed no change in cdc2 expression, but CDK6 levels increased with 5-FU treatment in AGS cells. On the other hand, chrysin and the combination of chrysin and 5-FU decreased cdc 2 and cyclin B1 though downregulated p-Akt expression and upregulated p21 expression in AGS/FR cells. These results indicated that chrysin potentiated the anticancer effect of 5-FU via G2/M phase arrest (Fig. 3C).

\section{Discussion}

The results of the present study have indicated that the combination of chrysin and 5-FU had synergistic anticancer effects and overcame 5-FU resistance in vitro. These results confirm the findings of previous studies (18), which suggest that chrysin may be used as an anticancer agent for combined therapy. In one study, chrysin was co-administered with cisplatin in HepG2 liver cancer cells (19), with docetaxel in A549 non-small cell lung cancer cells (18), and with metformin in breast cancer cells (20), showing synergistic effects in all cases. The present study found that chrysin showed synergy with 5-FU, according to $\mathrm{CI}$ analysis. The combination of chrysin $(50 \mu \mathrm{M})$ and 5-FU $(25 \mu \mathrm{M})$ showed significant inhibition of cell viability, compared with that induced by chrysin or 5-FU alone, in AGS/FR cells and AGS cells (Fig. 1). As was the case in a previous study $(12,13)$, chrysin-treated cells showed a decrease in the MDR1 level (Fig. S3). However, AGS/FR cells exhibited a higher MDR1 level than AGS cells, but this was not significant. The combined effect of chrysin and 5-FU was difficult to understand as a mechanism by which chrysin inhibits the expression of MDR1 and then accumulates 5-FU in AGS or AGS/FR cells. Therefore, the results of the present study suggest a mechanism in which the combination of chrysin and 5-FU arrests the cell cycle. In a future study, it would be beneficial to evaluate the therapeutic efficacy of chrysin in an AGS/FR-derived xenograft model as the results of the present study were obtained at the in vitro level. Nevertheless, the anticancer effects of chrysin observed in this study were consistent with those in other in vivo studies. Therefore, the application of chrysin with 5-FU may be clinically implemented to treat patients with 5-FU-resistant gastric cancer.

The combination of chrysin and 5-FU upregulated p21 expression in AGS cells and AGS/FR cells (Fig. 2C). The cyclin-dependent kinase inhibitor, p21 serves a key role in the cell cycle and is regulated by various stimuli, including p53 (21), and the PI3K/Akt pathway (22). Several studies have reported that chrysin also exerted anticancer effects through upregulating p21-induced G1 phase arrest in A375 melanoma cells (8) and G2 phase arrest in esophageal squamous carcinoma (23). In the present study, chrysin induced G2/M phase arrest and 5-FU induced G0/G1 phase arrest in AGS cells. The combination of chrysin and 5-FU caused cell accumulation in the $\mathrm{S}$ phase, suggesting a complementary effect of cell arrest by chrysin and 5-FU (Fig. 3A). The S phase of the cell cycle inhibits cell growth though inhibition of DNA synthesis when stress-induced DNA damage occurs (24). 
These results correlated with $\mathrm{S}$ phase arrest through upregulated p53 and p21 expression (Fig. 2C).

AGS/FR cells exhibited downregulated p-Akt expression (Fig. 3C). Akt regulates cyclin-dependent kinase inhibitor p21 and the cell cycle. Phosphorylated Akt promotes cell growth and angiogenesis. Kim et al (25) reported that Akt signaling was overactivated in chemo-resistant colon cancer cells, and that inhibition of Akt signaling may be a good pharmacological target (25). In the present study, the combination of chrysin and 5-FU decreased p-Akt expression and increased p21 expression in AGS/FR cells. Increased $\mathrm{p} 21$ inhibits the cyclin $\mathrm{B} 1 / \mathrm{cdc} 2$ complex protein expression, with this complex regulating $\mathrm{G} 2 / \mathrm{M}$ phase. Therefore, the results of the present study indicated that the combination of chrysin and 5-FU induced G2/M phase arrest via inhibition of cdc 2 and cyclin B1 by p21 upregulation in AGS/FR cells.

As shown in Fig. 1C, AGS/FR cells were resistant to high doses of 5-FU $(100 \mu \mathrm{M})$. The present study found that co-treatment of chrysin with 5-FU caused similar effects to chrysin treatment alone. Nevertheless, the CI value of chrysin and 5-FU was $<1$ at $48 \mathrm{~h}$, suggesting synergy (Fig. 1E). It is possible that the combined effect of chrysin and 5-FU occurs though chrysin-induced cell arrest as previously described (8).

In conclusion, the combination of chrysin and 5-FU in AGS cells enhanced inhibition of cell viability through $\mathrm{S}$ phase arrest. Furthermore, the results of the present study suggested that chrysin improved 5-FU resistance via G2/M phase arrest in AGS/FR cells. These results indicated that chrysin potentiates the anticancer effect of 5-FU and may be utilized for the treatment of 5-FU resistant gastric cancer.

\section{Acknowledgements}

Not applicable.

\section{Funding}

The present study was supported by the Bio \& Medical Technology Development Program of the NRF funded by the Korean Government (grant no. 2015M3A9B6074045) and the NRF grant funded by the Korea government, MSIT (grant no. 2017R1A2B4008254).

\section{Availability of data and materials}

All data generated or analyzed during this study are included in this published article.

\section{Authors' contributions}

SYL and JJ were responsible for study conception and drafting this article. SKL established the AGS/FR cells. JJ reviewed the article and provided necessary suggestions. All authors read and approved the final manuscript.

\section{Ethics approval and consent to participate}

Not applicable.

\section{Patient consent for publication}

Not applicable.

\section{Competing interests}

The authors declare that they have no competing interests.

\section{References}

1. Bray F, Ferlay J, Soerjomataram I, Siegel RL, Torre LA and Jemal A: Global cancer statistics 2018: GLOBOCAN estimates of incidence and mortality worldwide for 36 cancers in 185 countries. CA Cancer J Clin 68: 394-424, 2018.

2. Longley DB, Harkin DP and Johnston PG: 5-fluorouracil: Mechanisms of action and clinical strategies. Nat Rev Cancer 3: 330-338, 2003.

3. Yu B and Xie J: Identifying therapeutic targets in gastric cancer: The current status and future direction. Acta Biochim Biophys Sin (Shanghai) 48: 90-96, 2016.

4. Kimchi-Sarfaty C, Ben-Nun-Shaul O, Rund D, Oppenheim A and Gottesman MM: In vitro-packaged SV40 pseudovirions as highly efficient vectors for gene transfer. Hum Gene Ther 13: 299-310, 2002.

5. Baguley BC: Multiple drug resistance mechanisms in cancer. Mol Biotechnol 46: 308-316, 2010.

6. Thomas DM and Zalcberg JR: 5-fluorouracil: A pharmacological paradigm in the use of cytotoxics. Clin Exp Pharmacol Physiol 25: 887-895, 1998.

7. Jung J: Emerging utilization of chrysin using nanoscale modification. J Nanometer 2016: 7, 2016.

8. Pal-Bhadra M, Ramaiah MJ, Reddy TL, Krishnan A, Pushpavalli SN, Babu KS, Tiwari AK, Rao JM, Yadav JS and Bhadra U: Plant HDAC inhibitor chrysin arrest cell growth and induce p21WAF1 by altering chromatin of STAT response element in A375 cells. BMC Cancer 12: 180, 2012.

9. Lin YM, Chen CI, Hsiang YP, Hsu YC, Cheng KC, Chien PH, Pan HL, Lu CC and Chen YJ: Chrysin attenuates cell viability of human colorectal cancer cells through autophagy induction unlike 5-fluorouracil/oxaliplatin. Int J Mol Sci 19: 1763, 2018.

10. Xia Y, Lian S, Khoi PN, Yoon HJ, Joo YE, Chay KO, Kim KK and Do Jung Y: Chrysin inhibits tumor promoter-induced MMP-9 expression by blocking AP-1 via suppression of ERK and JNK pathways in gastric cancer cells. PLoS One 10: e0124007, 2015.

11. Sawicka D, Car H, Borawska MH and Niklinski J: The anticancer activity of propolis. Folia Histochem Cytobiol 50: 25-37, 2012.

12. Schumacher M, Hautzinger A, Rossmann A, Holzhauser S, Popovic D, Hertrampf A, Kuntz S, Boll M and Wenzel U: Chrysin blocks topotecan-induced apoptosis in Caco-2 cells in spite of inhibition of ABC-transporters. Biochem Pharmacol 80: 471-479, 2010.

13. Gyémánt N, Tanaka M, Antus S, Hohmann J, Csuka O, Mándoky L and Molnár J: In vitro search for synergy between flavonoids and epirubicin on multidrug-resistant cancer cells. In vivo 19: 367-374, 2005.

14. Hasan MM, Islam MS, Hoque KMF, Haque A and Reza MA: Effect of Citrus macroptera fruit pulp juice on alteration of caspase pathway rendering anti-proliferative activity against Ehrlich's ascites carcinoma in mice. Toxicol Res 35: 271-277, 2019.

15. Chou TC: Drug combination studies and their synergy quantification using the Chou-Talalay method. Cancer Res 70: 440-446, 2010.

16. Ittiudomrak $\mathrm{T}$, Puthong $\mathrm{S}$, Roytrakul $\mathrm{S}$ and Chanchao $\mathrm{C}$ : $\alpha$-Mangostin and apigenin induced cell cycle arrest and programmed cell death in SKOV-3 ovarian cancer cells. Toxicol Res 35: 167-179, 2019.

17. Jung J, Song DY, Hwang JJ, Park HJ, Lee JS, Song SY, Jeong SY and Choi EK: Induction of p53-mediated senescence is essential for the eventual anticancer therapeutic effect of RH1. Arch Pharm Res 42: 815-823, 2019.

18. Lim HK, Kim KM, Jeong SY, Choi EK and Jung J: Chrysin increases the therapeutic efficacy of docetaxel and mitigates docetaxel-induced edema. Integr Cancer Ther 16: 496-504, 2017.

19. Li X, Huang JM, Wang JN, Xiong XK, Yang XF and Zou F: Combination of chrysin and cisplatin promotes the apoptosis of Hep G2 cells by up-regulating p53. Chem Biol Interact 232: 12-20, 2015. 
20. Rasouli S and Zarghami N: Synergistic growth inhibitory effects of chrysin and metformin combination on breast cancer cells through hTERT and cyclin D1 suppression. Asian Pac J Cancer Prev 19: 977-982, 2018.

21. Tao J, Zhi X, Tian Y, Li Z, Zhu Y, Wang W, Xie K, Tang J, Zhang X, Wang L and Xu Z: CEP55 contributes to human gastric carcinoma by regulating cell proliferation. Tumour Biol 35: 4389-4399, 2014.

22. Matsuoka $\mathrm{T}$ and Yashiro M: The role of PI3K/Akt/mTOR signaling in gastric carcinoma. Cancers (Basel) 6: 1441-1463, 2014.

23. Khoo BY, Chua SL and Balaram P: Apoptotic effects of chrysin in human cancer cell lines. Int J Mol Sci 11: 2188-2199, 2010

24. Agarwal ML, Agarwal A, Taylor WR, Chernova O, Sharma Y and Stark GR: A p53-dependent S-phase checkpoint helps to protect cells from DNA damage in response to starvation for pyrimidine nucleotides. Proc Natl Acad Sci USA 95: 14775-14780, 1998.
25. Kim EJ, Kang GJ, Kang JI, Boo HJ, Hyun JW, Koh YS, Chang WY, Kim YR, Kwon JM, Maeng YH, et al: Over-activation of AKT signaling leading to 5-Fluorouracil resistance in SNU-C5/5-FU cells. Oncotarget 9: 19911-19928, 2018.

This work is licensed under a Creative Commons Attribution-NonCommercial-NoDerivatives 4.0 International (CC BY-NC-ND 4.0) License. 